\title{
An Analysis Method of Carrying Capacity Accuracy of Three-Row Roller Slewing Bearing
}

\author{
Peiyu HE*, Yun WANG*, Hua WANG** \\ *School of Mechanical Engineering, Jiangsu University, Zhenjiang, Jiangsu 212013, China, \\ E-mails: 1000005029@ujs.edu.cn (Corresponding Author); wangyun@ujs.edu.cn \\ **School of Mechanical and Power Engineering, Nanjing Tech University, Nanjing 211816, China, \\ E-mail:wangh@njtech.edu.cn \\ crossref http://dx.doi.org/10.5755/j02.mech.28111
}

\section{Introduction}

Three-row roller slewing bearings are the core components of large-scale rotating equipment, which consists mainly of three-row rollers, slewing rings and spacer blocks, as shown in Fig. 1. It is a large-sized structure (a maximum diameter of $40 \mathrm{~m}$ ) and subjected to a combination of large axial, radial and overturning moment loads. The maximum thrust of the slewing bearings can reach 170,000 $\mathrm{kN}$ under heavy load conditions and the maximum torque can reach $125,000 \mathrm{kN} \cdot \mathrm{m}$ [1]. The contact area between the rolling element and the raceway is very small, and the contact stress is extremely high. When an accident occurs, the maintenance is very difficult and expensive, which will affect the progress of the project. Therefore, the carrying capacity of the slewing bearing needs to be carefully calculated to improve the reliability of the slewing bearing.

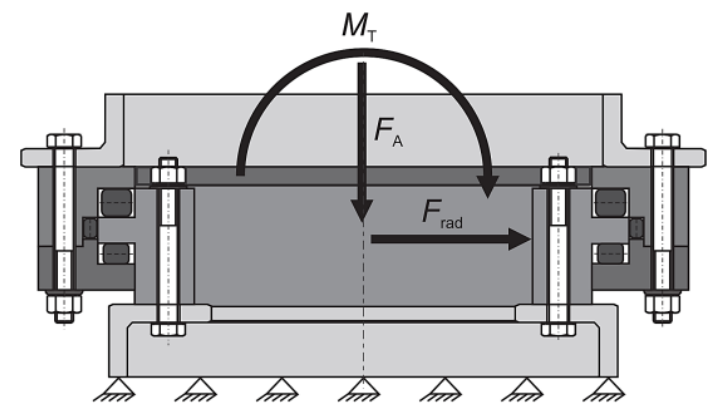

Fig. 1 Structure of three-row roller slewing bearing [2]

There are mainly two methods to calculate the carrying capacity of three-row roller slewing bearing. One is the analytical method based on the Hertz contact theory, and the other is the numerical method based on the finite element modeling. The mechanical results such as the contact stress and the deformation of the contact area between the roller and the raceway are analyzed by the Hertz contact theory [3]. When the actual structural conditions do not meet the assumption of the Hertz contact theory, the accurate results cannot be obtained. Scholars [4-6] thus established the finite element model of the slewing bearing to study the contact between the roller and raceway of slewing bearings, and the results are more in line with the experimental results under heavy loads than the results from the Hertz theory. The contact pairs between rolling elements and raceways of the slewing bearing can reach several thousand. Thus, many scholars use nonlinear springs and super-cells to simulate the contact behavior between rolling elements and raceways to improve calculation efficiency and reduce calculation difficulty [2, 7-9]. A tradeoff between accuracy and efficiency of the finite element model needs to be achieved by choosing appropriate mesh sizes $[5,10,11]$.

The finite element model needs to be verified, and the mesh size of the finite element model is of great significance for the calculation of the carrying capacity accuracy of the three-row roller slewing bearing. Therefore, the local and overall finite element models of three-row roller slewing bearing are established to study the effect of finite element mesh sizes on the carrying capacity accuracy in this paper. Strain tests are used to verify the finite element model. The method to improve the calculation accuracy and efficiency of the carrying capacity of the slewing bearing is studied, which is of great significance to the design of the slewing bearing and the practical application of the engineering.

\section{Local finite element model of three-row roller slewing bearings}

\subsection{Hertz contact theory}

Hertz studied the load-deformation of two contact objects under some assumptions. Fig. 2 shows the contact diagram of two cylinders. The maximum contact stress can be calculated as:

$$
\begin{aligned}
& \sigma_{\max }=\frac{2 Q}{\pi l b}, \\
& b=\sqrt{\frac{4 Q}{\pi L} \frac{\frac{1-u_{1}^{2}}{E_{1}}+\frac{1-u_{2}^{2}}{E_{2}}}{\frac{1}{\rho_{1}} \pm \frac{1}{\rho_{2}}}},
\end{aligned}
$$

where: $b$ is the contact ellipse short half axis; $E_{1}$ is the elastic modulus of contact object $1 ; E_{2}$ is the elastic modulus of contact object $2 ; l$ is the roller length; $Q$ is the contact load; $u_{1}$ is the Poisson's ratio of contact object $1 ; u_{2}$ is the Poisson's ratio of contact object $2 ; \sigma_{\max }$ is the maximum contact stress; $\rho_{1}$ is the curvature radius $1 ; \rho_{2}$ is the curvature radius 2 .

The contact area and contact stress of the contact surface between the rolling element and the raceway can be determined by the Hertz contact theory, which lays a foundation for determining the finite element mesh size. 


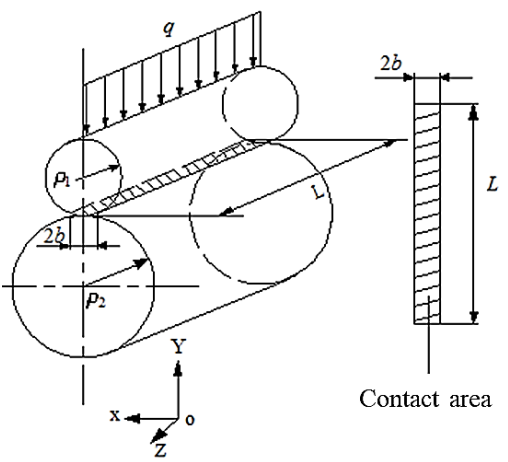

Fig. 2 Contact between two rollers

2.2. Local finite element contact model of three-row roller slewing bearing

\subsubsection{Structure of the three-row roller slewing bearing}

The 130-20-1005 three-row roller slewing bearing is selected and the dimensions are shown in Fig. 3. The diameters and lengths of the upper and lower rollers are 20 $\mathrm{mm}$ and the number of rollers of each row is 120 . The diameter and length of the middle rollers are $12 \mathrm{~mm}$ and the number of rollers is 180 . The diameters of the upper and lower rows of the raceways are $1005 \mathrm{~mm}$. The diameter of the middle row of raceway is $971 \mathrm{~mm}$. An axial force $F_{a}$ of 59,660 $\mathrm{N}$ and an overturning moment $M$ of $41,7620,000 \mathrm{~N} \cdot \mathrm{mm}$ are applied to the three-row roller slewing bearing. The maximum contact load between the roller and the raceway is obtained by the following equation $[8,11]$ :

$$
Q_{\max }=\frac{4 M}{n D}+\frac{F_{a}}{n}
$$

where: $D$ is the raceway diameter; $F_{a}$ is the axial load; $M$ is the overturning moment; $n$ is the roller number; $Q_{\max }$ is the maximum contact load.

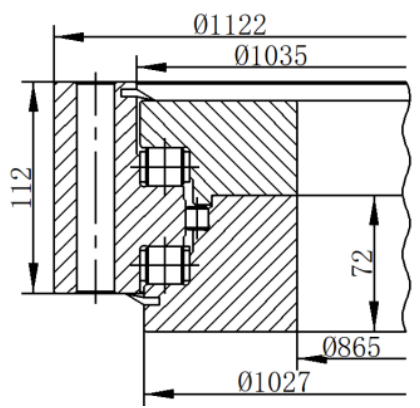

Fig. 3 Dimensions of 130-20-1005 three-row roller slewing bearing

The calculated maximum contact load is $14349 \mathrm{~N}$, which is the load applied to the local contact model of raceway and roller.

\subsubsection{Local contact model of the three-row roller slewing bearing}

A quarter of the roller and raceway is modeled to reduce the computational time, as shown in Fig. 4. The bottom surface of the raceway is fully constrained. A reference point RP-1 is set above the roller and coupled to the upper surface of the roller. One-fourth of the load obtained by
Eq. (3) is applied to the reference point. The translational degree of freedom in the $\mathrm{Y}$ direction of the reference point is released and the degrees of freedom in other directions are constrained. The chamfer angle of the roller is $0.7 \mathrm{~mm}$ according to GB/T 4661-2002 [12].

The elastic modulus of the slewing bearing material is chosen to be $207 \mathrm{GPa}$ and the Poisson's ratio is 0.3 [8]. The finite element mesh type is C3D8I. Different mesh size is set from $0.5 \mathrm{~mm}$ to $0.04 \mathrm{~mm}$ to investigate the effect of the mesh size. The finite element models with coarsest and finest meshing are shown in Fig. 5.

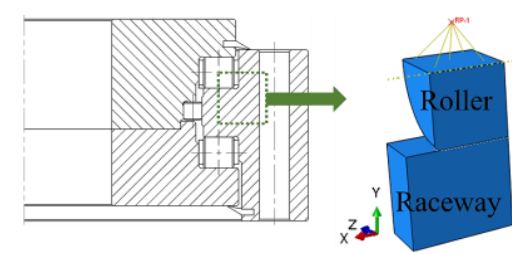

Fig. 4 Local finite element contact model of three-row roller slewing bearings

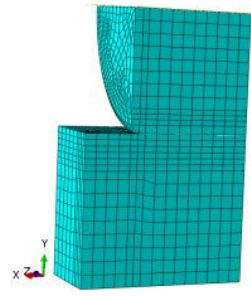

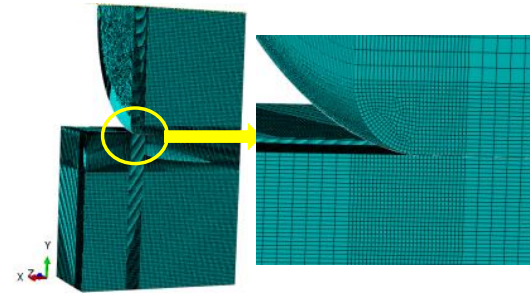

$\mathrm{b}$
Fig. 5 Local finite element model a) mesh size $0.5 \mathrm{~mm}$; b) mesh size $0.04 \mathrm{~mm}$

2.2.3. Simulation results of local contact model of the threerow roller slewing bearing

The simulation results of the equivalent stress with different meshing size are shown in Fig. 6. When the mesh size decreases, the maximum equivalent stress and contact stress on the raceway increases. The smaller finite element mesh results in the smaller high-stress region as shown in Fig. 7, a. The maximum equivalent stress is located below the raceway contact surface, and the stress distribution is smooth; The large finite element mesh size has a large highstress region as shown in Fig. 7, b. The stress distribution is not smooth, which is prone to calculation errors.

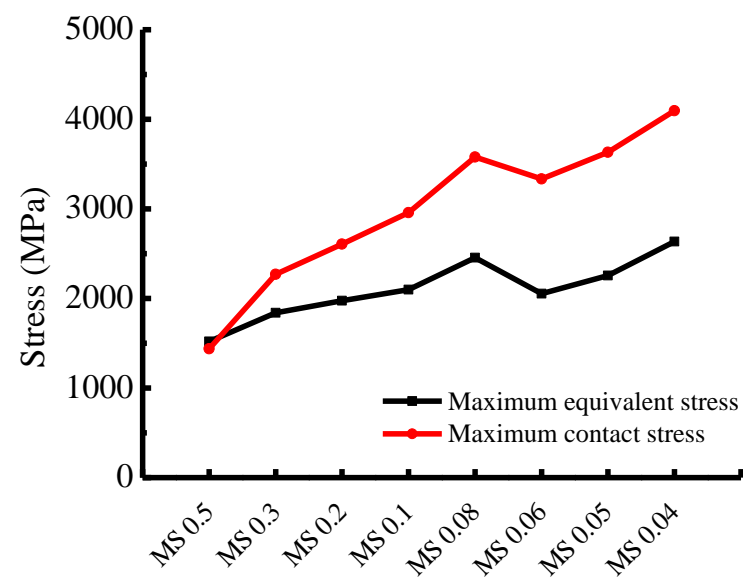

Fig. 6 Calculation results of local finite element contact model 


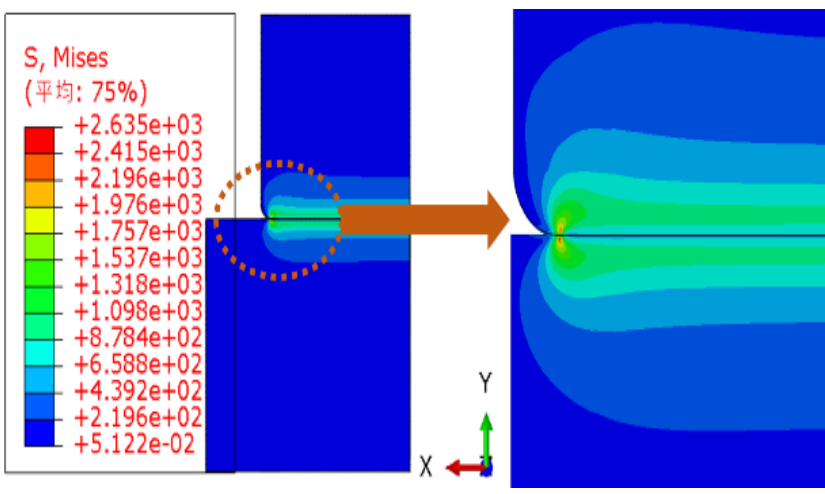

a

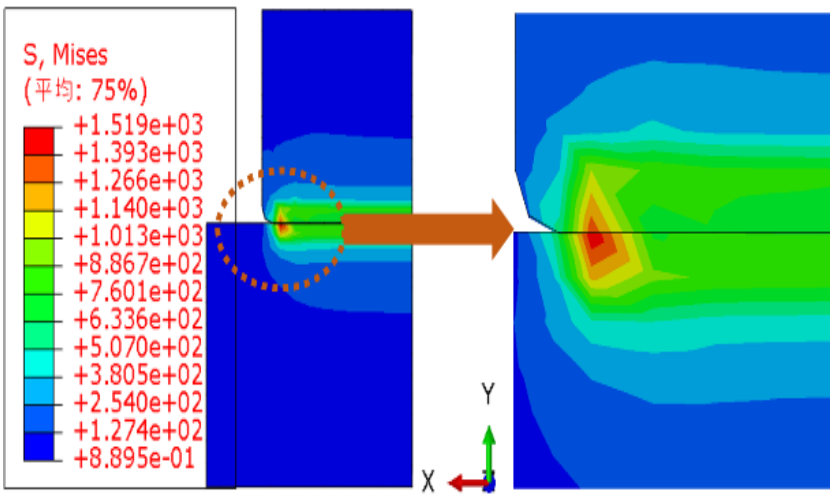

b

Fig. 7 Equivalent stress contour of raceway contact a) MS 0.04 ; b) MS 0.5

The maximum contact stress and the position of the contact area between the roller and the raceway of each model are different, as shown in Fig. 8. The contact stress distribution in the middle part of the contact between the raceway and the roller is stable, but it increases sharply at the end of the contact area between the roller and the raceway. The local stress concentration causes the area to be prone to plastic deformation, pitting corrosion, and other faults, which seriously affects the carrying capacity of the three-row roller slewing bearing. The carrying capacity accuracy of the raceway is evaluated by comparing the average contact stress of different contact lengths between the roller and the raceway with the Hertz contact theory in this paper, which avoids the impact of the chamfer of the roller on the calculation results.

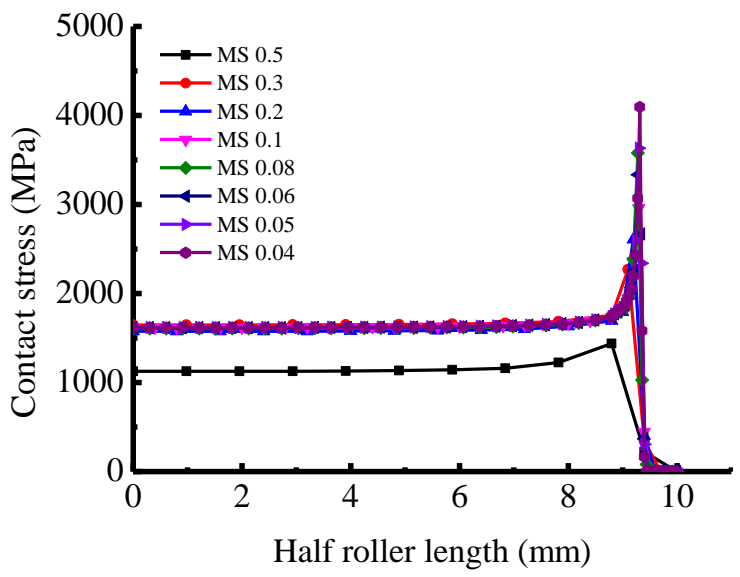

Fig. 8 Contact stress curve of raceway under different finite element mesh sizes
The average contact stress of the $40 \%$ contact length in the middle of the contact surface between the roller and the raceway with different mesh size is compared, as shown in Fig. 9. The difference with the Hertz theory becomes smaller as the finite element mesh size becomes smaller, and drops to $0.25 \%$ with the mesh size of $0.06 \mathrm{~mm}$. Fig. 10 shows the average contact stress of the $90 \%$ contact length in the middle of the contact surface between the roller and the raceway. It is shown that the differences with Hertz results are greater than that of the $40 \%$ contact length (Fig. 9 ), indicating the effect of the stress concentration at the end of the roller and the contact area of the raceway. The deviation from Hertz theory results decreases and then increases with the mesh size becoming smaller. The smallest deviation is found at the mesh size of $0.08 \mathrm{~mm}$. The results of the mesh size of $0.08 \mathrm{~mm}$ are closest to Hertz results based on the results in Fig. 8-10, and selected as the mesh size in the following simulations.

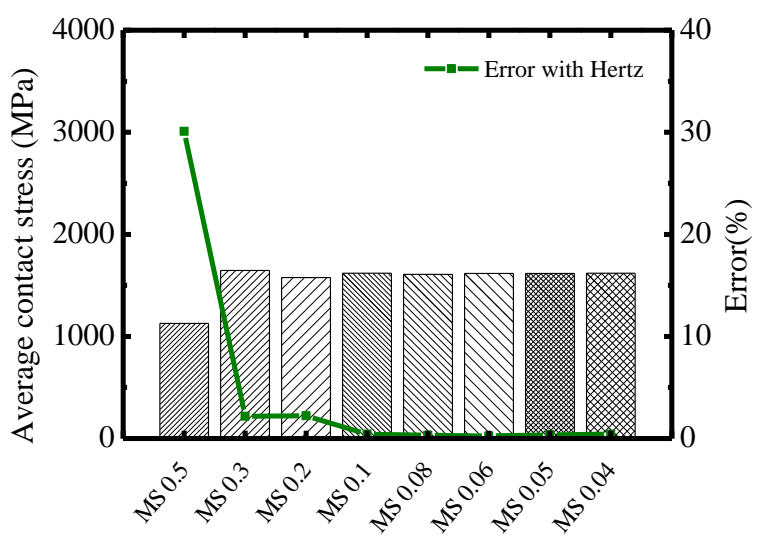

Fig. 9 Comparison of average contact stress of the $40 \%$ contact length in the middle of the contact surface of the raceway

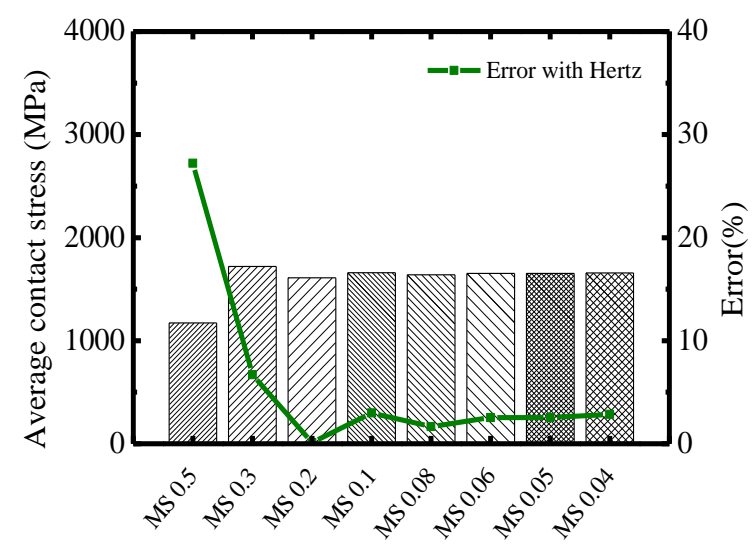

Fig. 10 Comparison of average contact stress of the $90 \%$ contact length in the middle of the contact surface of the raceway

To characterize the dispersion degree of the stresses on the contact line of the three-row roller slewing bearing, the stress variance and the stress concentration factor (the ratio of the maximum contact stress to the average contact stress on the raceway contact line) are calculated using Eqs. (4) and (5), and the results are plotted in Fig. 11.

$$
p=\frac{\sum\left(p_{j}-\bar{p}\right)^{2}}{n_{1}},
$$




$$
K=\frac{\sigma_{\max }}{\sigma_{m}}
$$

where: $K$ is the stress concentration factor; $n_{1}$ is the number of stress data; $p$ is the variance; $\bar{p}$ is the average stress on the raceway contact line; $p_{j}$ is the various stress points on the raceway contact line; $\sigma_{\max }$ is the maximum contact stress; $\sigma_{m}$ is the average contact stress.

As the finite element mesh size decreases, the SV and SCF increase, as shown in Fig. 11. If the stress variance of the raceway surface is too large, the contact stress of the raceway changes greatly, and the stress gradient is large.

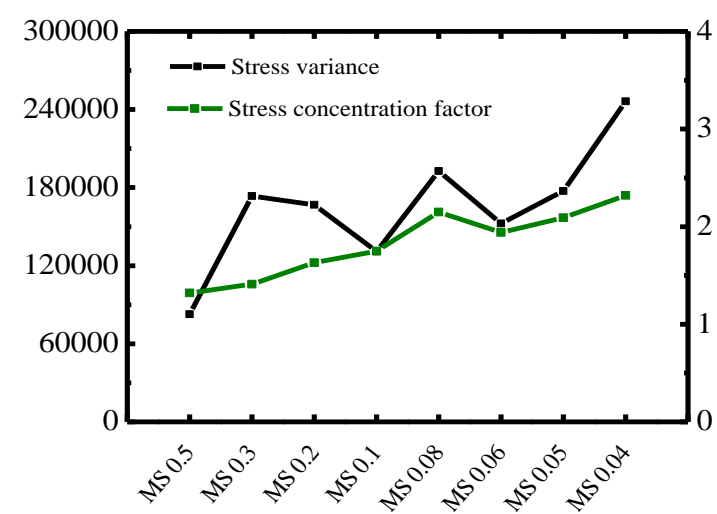

Fig. 11 Comparison of SCF (Stress concentration factor) and SV (Stress variance) on the raceway surface

2.3. Local finite element spring model of three-row roller slewing bearing

Non-linear springs are used to represent the roller to calculate the carrying capacity of the slewing bearing, which can reduce the finite element model size effectively, make the convergence easier, and improve the calculation efficiency. The roller represented by two non-linear springs is used to obtain the accurate contact load in the local finite element contact model of the slewing bearing [8], as shown in Fig. 12. The bottom surface of the lower raceway is fully constrained. A reference point RP-1 is set above the upper raceway and coupled to the upper surface of the upper raceway. The load is applied to the reference point. The translational degree of freedom in the $\mathrm{Y}$ direction and rotation degree of freedom in the $\mathrm{Z}$ direction of the reference point is released. Others degrees of freedom in other directions are constrained. The finite element mesh type is C3D8I.
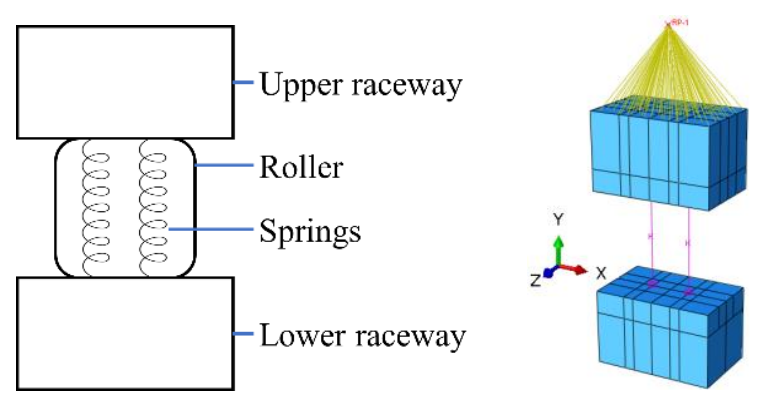

Fig. 12 Local spring finite element model of the slewing bearing

Some common empirical formulas are used to calculate the roller load-deformation curve of the slewing bear- ing [13-16]. The effect of the roller diameter on the deformation is not considered. The results show that the large diameter of the cylindrical roller has small deformation under the same load, and formulas considering the effect of diameter of the roller are derived [17], and the above empirical formulas are modified accordingly:

$$
\begin{aligned}
& Q=\frac{l^{\frac{8}{9}}}{\left(3.84 \times 10^{-5}\right)^{\frac{10}{9}}} \delta^{\frac{10}{9}}=K_{1} \delta^{\frac{10}{9}}, \\
& Q=\frac{l^{\frac{8}{9}} D_{w}^{\frac{1}{9}}}{\left(3.84 \times 10^{-5}\right)^{\frac{10}{9}} *\left(10 l^{0.6}\right)^{\frac{1}{9}}} \delta^{\frac{10}{9}}=K_{2} \delta^{\frac{10}{9}}, \\
& Q=\frac{l^{\frac{850}{925}}}{\left(4.05 \times 10^{-5}\right)^{\frac{1000}{925}}} \delta^{\frac{1000}{925}}=K_{3} \delta^{\frac{1000}{925}} \\
& Q=\frac{l^{\frac{850}{925}}}{\left(4.05 \times 10^{-5}\right)^{\frac{1000}{925}}} * \frac{D_{w}^{0.1}}{l^{0.06}} \delta^{\frac{1000}{925}}=K_{4} \delta^{\frac{1000}{925}}, \\
& Q=\frac{l^{\frac{8}{9}}}{\left(3.95 \times 10^{-5}\right)^{\frac{10}{9}}} \delta^{\frac{10}{9}}=K_{5} \delta^{\frac{10}{9}}, \\
& Q=\frac{l^{\frac{8}{9}} D_{w}^{\frac{1}{9}}}{\left(3.95 \times 10^{-5}\right)^{\frac{10}{9}} *\left(10 l^{0.6}\right)^{\frac{1}{9}}} \delta^{\frac{10}{9}}=K_{6} \delta^{\frac{10}{9}}
\end{aligned}
$$

where: $D_{w}$ is the roller diameter; $K_{1}$ is the spring stiffness 1 ; $K_{2}$ is the spring stiffness $2 ; K_{3}$ is the spring stiffness $3 ; K_{4}$ is the spring stiffness $4 ; K_{5}$ is the spring stiffness $5 ; K_{6}$ is the spring stiffness $6 ; l$ is the roller length; $Q$ is the contact load; $\delta$ is the deformation.

Fig. 13 shows the spring stiffness by different calculation formulas, and the calculated deformation is different under the same load. When a three-row roller slewing bearing is subjected to the radial force, the loaded ferrule will be displaced radially, and loaded ferrule will rotate slightly with an overturning moment applied, as shown in Fig. 14. The load-deformation curve of the nonlinear spring calculated using Eq. (7) is selected to analyze the influence of the offset and declination between the upper and lower raceways on the finite element spring model, as shown in Fig.15.

180 rollers are in the middle row of the 130-201005 three-row roller slewing bearing, which are used to bear the radial force. The radial force is relatively small compared with the axial force and the overturning moment, so the offset between the upper and lower raceways is small, set from $0 \sim 2 \mathrm{~mm}$. The limited offset between the upper and lower raceways does not substantially affect the load on the spring, the maximum error of the spring 1 and 2 loads is $0.5 \%$, as shown in Table 1 . Therefore, the slight offset of the inner and outer rings after applying the radial force does not 
affect the spring load in the finite element model of the slewing bearing.

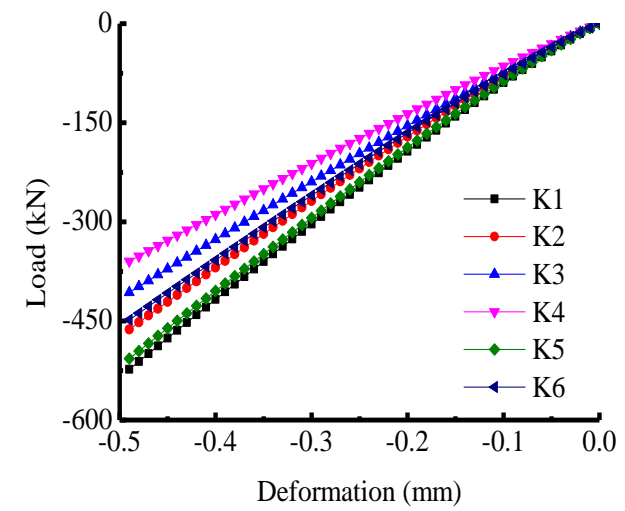

Fig. 13 Different spring load-deformation curves

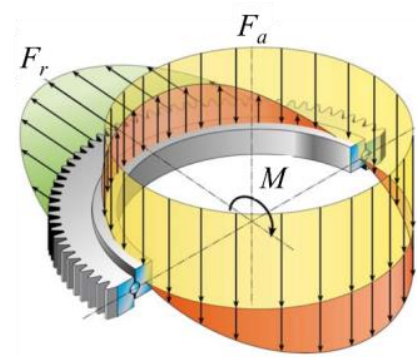

Fig. 14 Schematic diagram of slewing bearing [18]

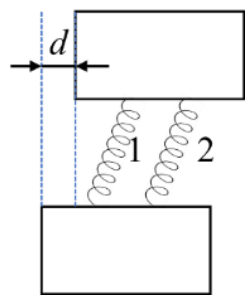

a

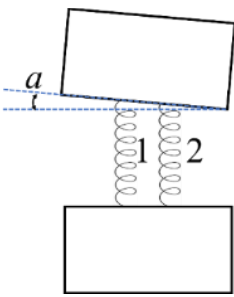

b
Fig. 15 Local spring finite element model of the slewing bearing a) offset model; b) declination model

The upper raceway of the slewing bearing is deflected by the overturning moment in the declination model, and the results are shown in Table 2. The load on the nonlinear spring under different declinations is unchanged and the maximum error of the spring 1 and 2 load value is $0.1 \%$. The load of the spring 2 is larger than that of the spring 1 . The load sum of the two springs is substantially the same at different declination angles, indicating that the slight deflection of the inner and outer rings from the radial force does not affect the spring transfer load and the sum of the spring loads at different declinations angle is the same.

Table 1

Finite element results of offset model of local spring models

\begin{tabular}{|c|c|c|}
\hline $\begin{array}{c}\text { Offset distance } d, \\
\mathrm{~mm}\end{array}$ & Spring 1 load, N & Spring 2 load, N \\
\hline 0 & -7175 & -7175 \\
\hline 0.2 & -7175 & -7175 \\
\hline 0.6 & -7178 & -7178 \\
\hline 1 & -7184 & -7184 \\
\hline 2 & -7211 & -7211 \\
\hline
\end{tabular}

Table 2

Finite element results of the declination model of local spring models

\begin{tabular}{|c|c|c|c|}
\hline $\begin{array}{c}\text { Deflection } a, \\
\mathrm{o}\end{array}$ & $\begin{array}{c}\text { Spring 1 load, } \\
\mathrm{N}\end{array}$ & $\begin{array}{c}\text { Spring 2 load, } \\
\mathrm{N}\end{array}$ & $\begin{array}{c}\text { Sum of loads, } \\
\mathrm{N}\end{array}$ \\
\hline 0 & -7175 & -7175 & -14350 \\
\hline 1 & -7174 & -7175 & -14349 \\
\hline 2 & -7174 & -7175 & -14349 \\
\hline 3 & -7173 & -7176 & -14349 \\
\hline 4 & -7173 & -7176 & -14349 \\
\hline 10 & -7170 & -7179 & -14349 \\
\hline
\end{tabular}

\section{Overall finite element model of three-row roller slew-} ing bearing

The axial force and the overturning moment are applied to the model, so the middle row of rollers is ignored. A half slewing bearing is modeled to reduce the computation time and two nonlinear springs are used to represent the roller in the calculation, as shown in Fig. 16. The reference point RP-1 is established at the geometric center of the slewing bearing and is coupled with the upper surface of the outer ring. The Z-direction translational freedom and the Yaxis rotational freedom of the RP-1 are released, and other degrees of freedom are constraint. The bottom surface of the inner ring is fully constrained. Half of the overall model load (the axial force $29,830 \mathrm{~N}$ and the overturning moment $208,810,000 \mathrm{~N} \cdot \mathrm{mm}$ ) is applied to the reference point PR-1. The elastic modulus is $207 \mathrm{GPa}$ and the Poisson's ratio is 0.3 .

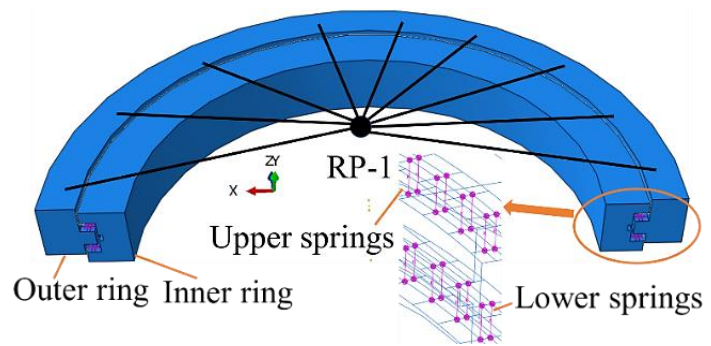

Fig. 16 Overall finite element model of three-row roller slewing bearings

3.1. Effect of spring stiffness coefficient and finite element mesh size on carrying capacity of slewing bearings

The spring stiffness $\mathrm{K} 1, \mathrm{~K} 2$, and $\mathrm{K} 4$ located in the upper, middle and lower sections of Fig. 13 are selected and substituted into the overall finite element model of the slewing bearing. The influence of the spring stiffness and finite element mesh size on the carrying capacity accuracy of the slewing bearing is analyzed. The larger deformation zone is located at both ends of the overturning moment, as shown in Fig. 17.

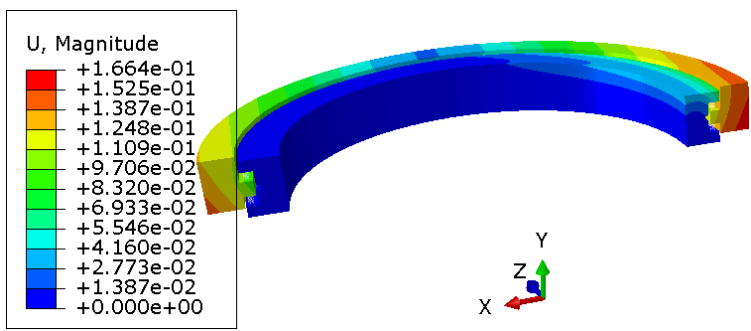

Fig. 17 The full circle deformation of the slewing bearing with the spring stiffness $\mathrm{K} 1$ and the mesh size $2 \mathrm{~mm}$ 
As the finite element mesh becomes larger, the deformation of the slewing bearing becomes smaller as shown in Fig. 18. This shows that different spring stiffness has a slight influence on the full circle deformation and spring load of the slewing bearing. The finite element mesh size has a great influence on the calculation results of the slewing bearing.

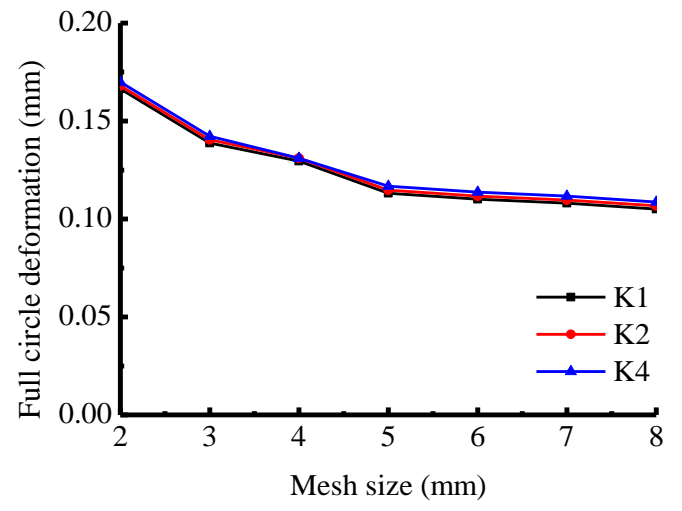

a

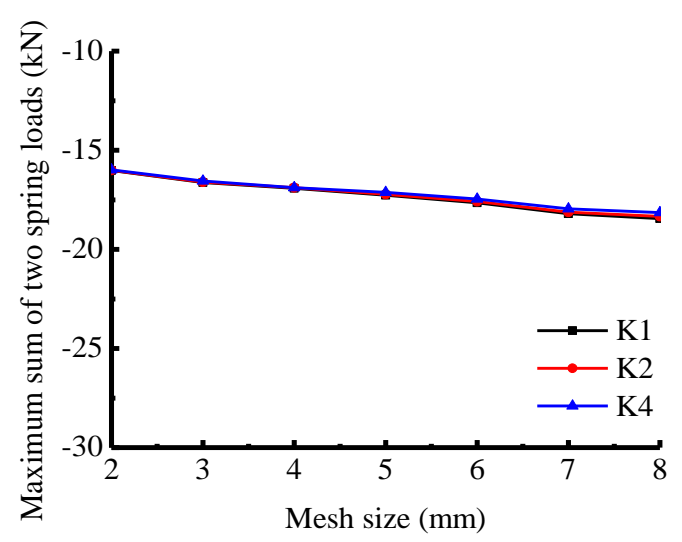

b

Fig. 18 Comparison of different spring stiffness results of slewing bearings (a) full circle deformation; (b) maximum sum of two spring loads

The load distribution in the overall finite element model is an important parameter for the carrying capacity of the slewing bearing. Fig. 19 shows the load distribution on springs with different finite element mesh sizes of the spring stiffness K2. The finite element mesh size is from $2 \mathrm{~mm}$ to $8 \mathrm{~mm}$ and the load value is the sum of loads of the two springs. The results show that the load of the upper row spring is greater than that of the lower row spring.

The position of the maximum load is the area where the couple of the axial force and the overturning moment is the maximum, and the maximum load of the slewing bearing determines the rolling element position of the maximum contact load, which provides data for the strength check of the inner and outer ring connecting bolts and determines the ferrule stiffness and the relative displacement between the fixed ferrule and the movable ferrule. With the finite element mesh becomes larger, the difference between the maximum load value on the spring and the load value obtained by the Eq. (3) becomes larger (the minimum error 9.37\%), as shown in Fig. 20, which is accepted. The load values of the two springs are different, and the load value of the spring 1 is greater than that of the spring 2, indicating that the overturning moment acts on the slewing bearing, causing it to deflect around the geometric center.

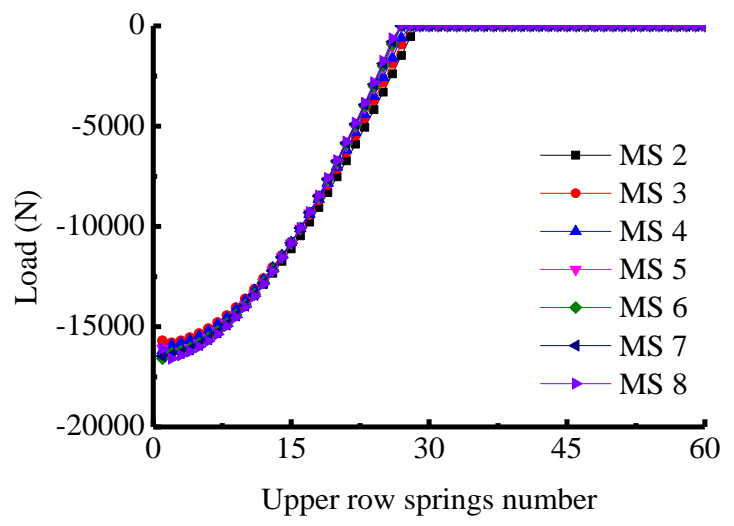

a

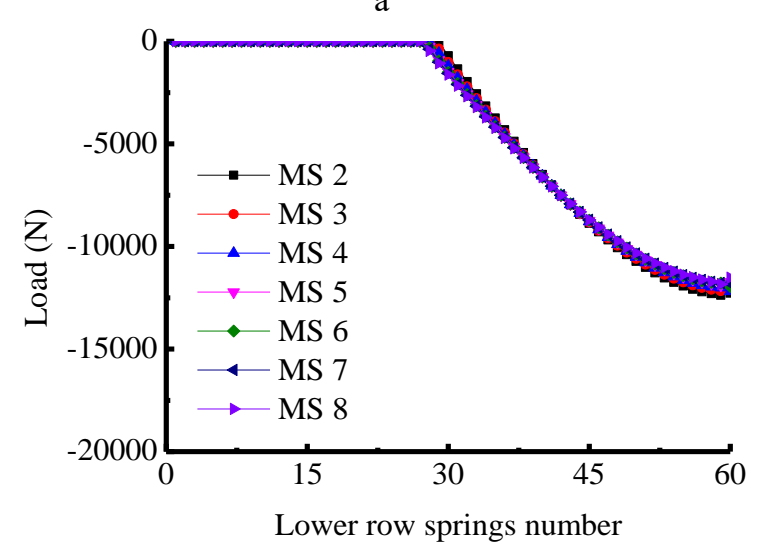

b

Fig. 19 Spring load distribution of three-row roller slewing bearing springs a) upper row of springs; b) lower row of springs

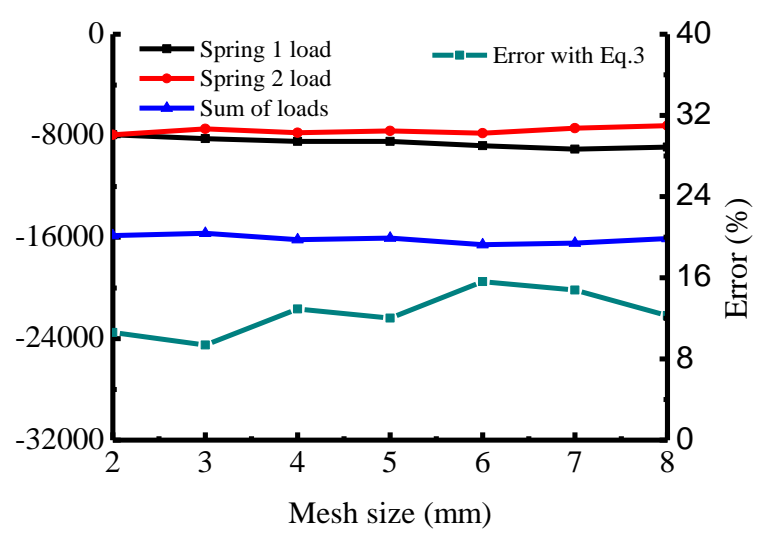

Fig. 20 Comparison of maximum spring load values instead of rollers in the overall model

3.2. Carrying capacity accuracy test of three-row roller slewing bearings

The static loading test is carried out by strain measurements on the slewing bearing test rig, as shown in Fig. 21. 36 strain gauges are placed on the inner circumference of the test slewing bearing to obtain the load distribution of the ferrule bearing ring. The deformation direction of the strain gauge adheres to the axial direction of the slewing bearing, and the temperature compensation is carried out. The axial force and the overturning moment are applied to the three- 
row roller slewing bearing by controlling the output pressure of a hydraulic cylinder. Three load measurements are carried out, and the average results are taken for comparison with the simulation results, as shown in Fig. 22.
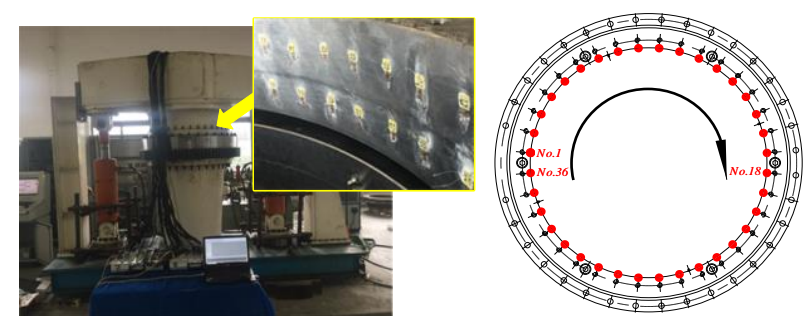

Fig. 21 Layout of the strain gauge measurement for the three-row roller slewing bearing

The trend of the deformation curve from the simulation agrees with that of the strain test, as shown in Fig. 22. With the mesh size of the finite element model becoming smaller, the differences on the deformation become smaller, and the difference between mesh size of $2 \mathrm{~mm}$ and $3 \mathrm{~mm}$ is only $2.03 \%$, indicating that the deformation results of the finite element model tend to be stable with small mesh sizes.

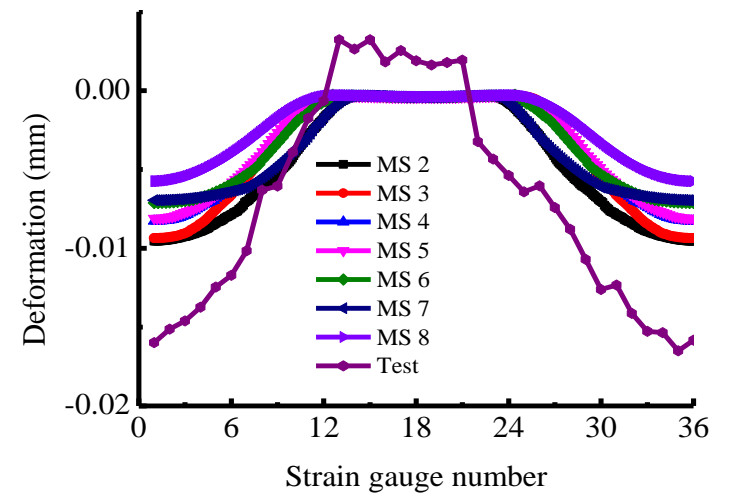

Fig. 22 Results of the deformation of the inner ring: comparison between the simulation results and test results

\section{Conclusions}

The local and overall finite element models of a three-row roller slewing bearings are established in this paper. Hertz contact theory and strain tests are used to study the influence of mesh size of the finite element model on the carrying capacity accuracy of three-row roller slewing bearings. The conclusions are as follows:

1) The mesh size of the finite element model can be verified by selecting the partial length of the contact line between the roller and the raceway. As the finite element mesh size becomes smaller, the deviation with the Hertz contact theory is smaller.

2) The displacement and the slight deflection between the upper and lower raceways of the finite element model of the three-row roller slewing bearing do not affect the load transfer of the spring.

3) As the mesh size of the overall finite element model increases, the full-circle deformation of the slewing bearing becomes smaller, and the maximum load of the two springs increases. The results show that different spring stiffness has little effect on the full-circle deformation and spring load of the slewing bearing. The spring load distribution trends of different finite element meshes are the same, but the number of loaded springs and the maximum spring load value are different.

The study of the finite element mesh size of the three-row roller slewing bearing is beneficial to improve the calculation accuracy and efficiency of the carrying capacity of the slewing bearing, which lays the foundation for the structural optimization and the reliability research of slewing bearings.

\section{Funding}

This study was funded by the National Natural Science Foundation of China (No. 51575245), and the China Postdoctoral Science Foundation (2020M671354).

\section{References}

1. Zhiling, N. 2019. Research on shield machine-stratigraphic similarity system in 3D geomechanical model test, Beijing University of Civil Engineering and Architecture, $45 \mathrm{p}$.

2. Peter, G.; Drobne, M.; Srečko G. 2013. Computational model for determination of dynamic load capacity of large three-row roller slewing bearing, Engineering Failure Analysis 32(9): 44-53. http://dx.doi.org/10.1016/j.engfailanal.2013.02.030.

3. Chao, L. 2018. Mechanical performance analysis and structural optimization design of slewing bearing, Kunming University of Science and Technology, $34 \mathrm{p}$.

4. Skyba, R.; Hrček, S.; Smetanka, L.; et al. 2018. Stiffness analysis of slewing bearings, IOP Conference Series Materials Science and Engineering 393: 1-6. http://dx.doi.org/10.1088/1757-899X/393/1/012060.

5. Peiyu, H.; Qinrong, Q.; Yun, W.; et al. 2021. Influence of finite element mesh size on the carrying capacity analysis of single-row ball slewing bearing, Advances in Mechanical Engineering13(4): 1-12. https://doi.org/10.1177/16878140211009030.

6. Ludwik, K.; Rafal, P.; Szczepan, S. 2018. Modification of the raceway profile of a single-row ball slewing bearing, Mechanism and Machine Theory 128: 1-15. http://dx.doi.org/10.1016/j.mechmachtheory.2018.05.009.

7. Peter, G.; Rok, P.; Srečko, G. 2013. Computational model for determination of static load capacity of threerow roller slewing bearings with arbitrary clearance and predefined raceway deformations, International Journal of Mechanical Sciences 73: 82-92. http://dx.doi.org/10.1016/j.ijmecsci.2013.04.012.

8. Peiyu, H.; Yun, W. 2021. Effect of high-strength bolts and supporting structures on the carrying capacity of three-row roller slewing bearings, Proceedings of the Institution of Mechanical Engineers, Part C: Journal of Mechanical Engineering Science 0: 1-12. https://doi.org/10.1177/0954406220949585.

9. Guanci, C.; Cunzhu, W.; Zhengming, X. 2016. Effects of supporting structure and bolt connection on the fatigue life and carrying capacity of a slewing bearing, Proceedings of the institution of mechanical engineers, Part J: Journal of Engineering Tribology 0(0): 1-17. http://dx.doi.org/10.1177/1350650116677606.

10. Satyanarayana, S.; Melkote, S. N. 2004. Finite element modeling of fixture-workpiece contacts: single 
contact modeling and experimental verification, International Journal o Machine Tools \& Manufacture 44(9): 903-913.

http://dx.doi.org/10.1016/j.ijmachtools.2004.02.010.

11. Kania, L. 2006. Modelling of rollers in calculation of slewing bearing with the use of finite elements, Mechanism \& Machine Theory 41(11): 1359-1376.

http://dx.doi.org/10.1016/j.mechmachtheory.2005.12.007.

12. GB/T 4661-2002. 2002. Rolling bearings - cylindrical rollers, In: People's republic of China machinery industry standards, China $6 \mathrm{p}$.

13. Samy, L.; Daniel, N.; Alexandre, L. 2014. Four-point contact ball bearing model with deformable rings, Journal of Ttribology 135(3): 928-931.

http://dx.doi.org/10.1115/1.4024103.

14. Harris, T. A. 2006. Rolling bearing analysis, New York: John Wiley\&Sonc Inc., $121 \mathrm{p}$.

15. Galmgren, L. 1949. Cylinder Compressed Between Two Planes Bodies, Sweden: SKF Gotebory, 87 p.

16. Johnson, K. L. 1985. Contact mechanics, Cambridge university press, $132 \mathrm{p}$.

17. Jiwei, L.; Tianyu, L. 2009. Analysis and calculation of rolling bearings, Beijing: Mechanical Industry Press, $6 \mathrm{p}$

18. IMO. 2019. DV 313D Slewing ring product catalogue. www.goimo.com.
P. Y. He, Y. Wang, H. Wang

\section{AN ANALYSIS METHOD OF CARRYING CAPACITY CCURACY OF THREE-ROW ROLLER SLEWING BEARING}

\section{S u m m a r y}

Three-row roller slewing bearings are the core components of large-scale rotating equipment. It has a large structural size and is subjected to heavy loads, which requires extremely high carrying capacity. The effect of finite element mesh size on the carrying capacity accuracy of three-row roller slewing bearing is investigated. A local finite element model is established to analyze the contact area between the roller and the raceway, which is compared with the Hertz contact theory to verify the reasonable mesh size of the finite element model. The local spring finite element model is established, and the effect of the mesh size on the offset and the declination of the upper and lower raceway is investigated; The overall finite element model of the slewing bearing is established to analyze the effect of the mesh size and the nonlinear spring stiffness on the carrying capacity accuracy. The whole circle deformation of the ring and the load distribution is investigated to determine the reasonable mesh size. This article provides a method and idea for the verification of the three-row roller slewing bearing finite element model, which is beneficial to improve the calculation accuracy of the bearing capacity of the three-row roller slewing bearing.

Keywords: three-row roller slewing bearing, carrying capacity, finite element mesh size, nonlinear spring stiffness, analysis accuracy.

Received January 15, 2021

Accepted October 04, 2021

This article is an Open Access article distributed under the terms and conditions of the Creative Commons Attribution 4.0 (CC BY 4.0) License (http://creativecommons.org/licenses/by/4.0/). 